\section{SAT0525 AN UPDATE ON PULMONARY ARTERY INVOLVEMENT IN BEHCET'S SYNDROME: MORE PULMONARY ARTERY THROMBOTIC DISEASE AND A BETTER OUTCOME}

Y. Ozguler ${ }^{1}$, E. Dincses ${ }^{1}$, S. Bakan ${ }^{2}$, G. Hatemi ${ }^{1}$, M. Melikoglu' ${ }^{1}$, S. Ugurlu ${ }^{1}$, S. Yurdakul ${ }^{1}$, H. Yazici ${ }^{1}$, E. Seyahi ${ }^{1}$. ${ }^{1}$ Department of Internal Medicine Division of Rheumatology, ${ }^{2}$ Department of Radiology, Istanbul University Cerrahpasa Medical Faculty, istanbul, Turkey

Background: Pulmonary artery involvement (PAI) is the most common form of arterial involvement in Behçet's syndrome (BS) and is a well-known cause of mortality and morbidity. A previous survey ${ }^{1}$ by our group had analysed the clinical characteristics and outcome of 47 pts with PAI registered between 2000-2007 and shown that: 1.the overwhelming male predominance was decreasing; 2. 1/4th of the pts had isolated pulmonary artery thrombosis (PAT); and 3. the mortality rate was $26 \%$ after a mean follow-up of 7 years. Recently we had the impression that female/male ratio was perhaps increasing, we are becoming to see more pts with isolated PAT and that we started to use more biologics.

Objectives: This survey was done to look at these assumptions formally in a recent group of BS pts with PAI.

Methods: We reviewed the records of about 3390 pts with BD who were registered at our multidisciplinary BS clinic between Jan 2008 and Jan 2018 From this group we identified $47(42 \mathrm{M} / 5 \mathrm{~F})$ pts who were diagnosed with PAI and recorded all information regarding clinical characteristics, outcome, radiological studies and medical or surgical treatment.

Results: The prevalence of pts with PAI decreased from $1.9 \%$ to $1.4 \%$ in the recent cohort. The $\mathrm{M} / \mathrm{F}$ ratio, the mean age at the onset of PAI were similar across 2 cohorts. The frequencies of other vascular involvement were almost similar to that observed in the previous cohort. However, there were more pts with neurological disease (parenchymal) in the recent cohort. As usual, PAT or PAA were mostly bilateral and involved descending lobar arteries. On the other hand, types of PAI involvement at presentation had changed substantially: those with isolated PAT reached a share of $45 \%$. Forty-five $(96 \%)$ pts received cyclophosphamide (Cy) pulses for a mean of $6 \pm 4$ courses, which was significantly shorter compared to that observed in the previous cohort. A total of $23(49 \%)$ pts received infliximab because of relapsing course, side effects or unresponsiveness to Cy for a mean follow-up of $8 \pm 4$ mo while only 2 pts received anti-TNF's in the older cohort. 4 pts had lung surgery. These were lobectomies in 3 pts due to giant rapidly progressing aneurysms and cavitectomy in 1 . Bronchial artery embolization was done in 3 pts because of refractory hemoptysis. , By Jan 2018 the outcome of information was available on $45 / 47$ pts: 4 pts (all male) ( $8 \%$ ) had died, 2 were lost to follow-up after 12 and 16 mo of follow-up and the remaining were alive after a median follow-up of 5 [IQR:3-9] years. The causes of deaths were massive hemoptysis in 3, severe pulmonary hypertension in 1 . As shown in the figure, the survival has improved significantly in the recent yrs.

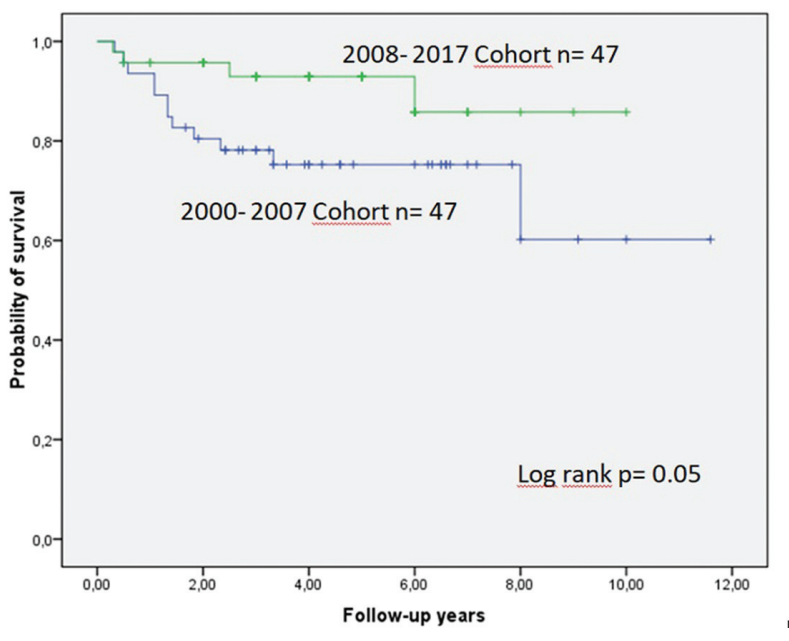

Conclusions: The surveys of 2 consecutive cohorts showed that the prevalence of PAI perhaps mildly decreased, isolated PAT type of involvement was with considerably higher frequency and the outcome was getting better. Cy is still the first agent in these pts however its duration of use became much shorter and antiTNF's mainly infliximab was used in about half of the cohort. The survival seems to have improved significantly. This could have been due to a decreased severity of the type of PAI, with isolated PAT becoming the most frequent type, or a better management.

REFERENCE:

[1] Seyahi E. Medicine (Baltimore) 2012.
Disclosure of Interest: None declared

DOI: 10.1136/annrheumdis-2018-eular.6675

\begin{tabular}{|l|l}
\hline SAT0526 & IS RELAPSE RATE OF GIANT CELL ARTERITIS IN \\
REAL-LIFE EXPERIENCE LOWER THAN IN THE \\
CONTROLLED TRIALS? RESULTS OF A \\
RETROSPECTIVE, MULTI-CENTRE COHORT STUDY
\end{tabular}

F. Alibaz-Oner ${ }^{1}$, M.A. Balcl' ${ }^{2}$, O.N. Pamuk ${ }^{3}$, O. Zengin ${ }^{4}$, M. Tascl ${ }^{5}$, A. Dogru', O. Bayındır ${ }^{7}$ S. Yavuz ${ }^{8}$, A. Cefle ${ }^{9}$, M.E. Tezcan ${ }^{10}$, M.F. Oksuz ${ }^{11}$, O. Kucuksahin $^{12}$, A. Omma ${ }^{13}$, S. Yasar Bilge $e^{14}$, T. Kasifoglu $^{14}$, Z. Erturk' ${ }^{1}$, C. Bes ${ }^{15}$, A.U. Unal', B. Armagan ${ }^{16}$, E. Gonullu ${ }^{17}$, A. Yazici ${ }^{9}$, O. Karadag ${ }^{16}$, E. Dalkilic ${ }^{18}$, K. Aksu $^{7}$, G. Keser ${ }^{7}$, H. Direskeneli ${ }^{1}{ }^{1}$ Rheumatology, Marmara University School of Medicine, Istanbul; ${ }^{2}$ Rheumatology, Gazi Yaşargil Education and Research Hospital, Diyarbakır, Turkey; ${ }^{3}$ Rheumatology, Private Practice, Boston, USA; ${ }^{4}$ Rheumatology, Adıaman University School of Medicine, Adıyaman;

${ }^{5}$ Rheumatology, Pamukkale University School of Medicine, Denizli;

${ }^{6}$ Rheumatology, Süleyman Demirel University School of Medicine, Isparta; ${ }^{7}$ Rheumatology, Ege University School of Medicine, Izmir, ${ }^{8}$ Rheumatology, Bilim University School of Medicine, Istanbul; ${ }^{9}$ Rheumatology, Kocaeli University School of Medicine, Kocaeli; ${ }^{10}$ Rheumatology, Kartal Lütfü KIrdar Education and Research Hospital, Istanbul; ${ }^{11}$ Rheumatology, Uludağ University School of Medicine, Bursa;

${ }^{12}$ Rheumatology, Yildırım Beyazıt University School of Medicine; ${ }^{13}$ Rheumatology, Ankara Numune Education and Research Hospital, Ankara; ${ }^{14}$ Rheumatology, Osmangazi University School of Medicine, Eskişehir, ${ }^{15}$ Rheumatology, Bakırkoy Sadi Konuk Education and Research Hospital, Istanbul; ${ }^{16}$ Rheumatology, Hacettepe University School of Medicine, Ankara; ${ }^{17}$ Rheumatology, Sakarya University School of Medicine, Sakarya; ${ }^{18}$ Rheumatology, Uludag University School of Medicine, Bursa, Turkey

Objectives: Corticosteroids (CS) are accepted as the standard first-line treatment for giant cell arteritis (GCA). However, controlled trials of tocilizumab and abatacept demonstrated relapse rates of up to $70 \%-80 \%$ in patients on CS-only protocols in 12-24 months. Though level of evidence is low and not suggested by guidelines (except for methotrexate), conventional immunosuppressives (ISs) are also commonly used. We aimed to assess the relapse rates in patients with GCA in routine practice, retrospectively.

Methods: We assembled a retrospective cohort of patients with GCA from Turkey. All data was abstracted from records. Relapse was defined as any new manifestation or increased acute-phase response leading to the change of the CS dose or use of a new therapeutic agent by the treating physician.

Results: The study included 156 (F/M: 95/61) patients with GCA (table 1). The mean age at disease onset was $67.8 \pm 9.1$ years. Polimyalgia Rheumatica was also present in $48(30,8 \%)$ patients. Diagnosis was proven histopathologically in 99 patients. All patients received $1 \mathrm{mg} / \mathrm{kg} /$ day CS for remission induction, additional CS pulses were given to $36(23.1 \%)$ patients. Conventional ISs including methotrexate and azathioprine were used in $89(56.1 \%)$ and $26(16.6 \%)$ patients respectively, while $10(6.4 \%)$ patients received biologic treatments (8 tocilizumab,2 etanercept). Fourty-four (28.2\%) patients used only CS during follow-up. Follow-up of at least 6 months was available for 132 patients, and median followup duration was 35 (6-268) months. Relapses occurred in $27(20.5 \%)$ patients during follow-up. Mortality rate was $7.5 \%(n=10)$ during follow-up. VDI score was $2.4 \pm 1.7$. Main causes of damage were related to CS treatments such as cataract, osteoporosis and diabetes mellitus.

\begin{tabular}{|c|c|}
\hline & Giant Coll Arternits (n=156) \\
\hline \multicolumn{2}{|l|}{ Manifestations of systemic inflammation, $n / 156(\%)$} \\
\hline Anemia ( $12 \mathrm{me} / \mathrm{d}$ for femalo, $13 \mathrm{me} / \mathrm{dl}$ for male) ) & $94(60.2 \%)$ \\
\hline Exthrocyte Sedimentation Rate (mm/hour). & $84.6 \pm 30.1$ \\
\hline Greactive protein (me//)" & $84.8 \pm 65.3$ \\
\hline Malaise & $132(84.68)$ \\
\hline Woleht loss & $72(46.16)$ \\
\hline Fever & $35(22.4 \%)$ \\
\hline Stiffness and/or pain muscles and Joints & $48(30.8 \%)$ \\
\hline \multicolumn{2}{|l|}{ Manifestations of Vascular ischemia, $n / 156(x)$} \\
\hline Headache & $144(92.38)$ \\
\hline Sealp Tenderness & $78(50 \%)$ \\
\hline Jaw Cloudication & $57(36.5 \%)$ \\
\hline Oeular Symptoms & $72(46.2 \%)$ \\
\hline Extremity Claudication & $14(8.9 \%)$ \\
\hline Neurological Manifertentions & $14(980)$ \\
\hline
\end{tabular}

Conclusions: In this first multi-centre series of GCA from Turkey, we observed that only one fifth of patients had relapses during a mean follow-up of 35 months. This lower relapse frequency suggests a different clinical spectrum in routine 
practice compared to patients included in controlled trials. Our results also suggest that there is a clear need for a steroid sparing agent in patients with GCA, that is a older aged population prone to CS side effects.

Disclosure of Interest: None declared

DOI: 10.1136/annrheumdis-2018-eular.3983

\section{SAT0527 RITUXIMAB PRESCRIPTION PATTERNS AND EFFICACY IN THE INDUCTION TREATMENT OF ANCA- ASSOCIATED VASCULITIS IN A BELGIAN MULTICENTRIC COHORT}

F. Vandergheynst ${ }^{1}$, P. Chasseur ${ }^{1}$, J.-B. Nicolas ${ }^{2}$, C. von Frenckell ${ }^{3}$, D. Blockmans ${ }^{4} .{ }^{1}$ Internal Medicine, Erasme Hospital, Brussels; ${ }^{2}$ Internal Medicine, CHU Mont-Godinne, Yvoir, ${ }^{3}$ Rheumatology, CHU Sart-Tilman, Liège; ${ }^{4}$ Internal Medicine, UZ Gasthuisberg, Leuven, Belgium

Background: The RAVE trial has revolutionised the induction treatment of ANCA-Associated Vasculitis (AAV, including GPA, granulomatosis with polyangiitis and MPA, microscopic polyangiitis), by demonstrating non-inferiority of rituximab compared with cyclophosphamide ${ }^{1}$.

Objectives: To study AAV patients' characteristics, rituximab prescription practices and efficacy in AAV induction treatment in 4 Belgian university hospitals. The patient population, selected according to the Belgian reimbursement criteria, is relatively homogeneous and comparable to the one of RAVE trial.

Methods: 57 patients, receiving rituximab as AAV induction therapy since May 2014, were enrolled in an observational retrospective multicenter trial involving 4 Belgian university hospitals. We have focused on the type of AAV (GPA/MPA), ANCA specificity (anti-PR3/MPO), prescriber's speciality, used reimbursement criteria, organ involvements, severity of the flares (according to BVAS-WG definition) and finally rituximab efficacy in AAV induction treatment by considering the RAVE primary (complete remission without prednisone) and secondary (complete remission with prednisone $<10 \mathrm{mg}$, rates of relapses) outcomes at $6,12,18$ and 24 months.

Results: The most frequent subtype of AAV was GPA (84\%). The main indication was relapsing disease $(54.4 \%)$, followed by contra-indication to cyclophosphamide $(38.6 \%)$. $66.7 \%$ of the patients reached complete remission with prednisone $<10 \mathrm{mg}$ at 6 months, and $55.3 \%$ at 12 months, $40 \%$ at 18 months, $25 \%$ at 24 months respectively. In the "severe disease" subgroup, $73 \%$ reached complete remission with prednisone $<10 \mathrm{mg}$ at 6 months, $58.8 \%$ at 12 months, $50 \%$ at 18 months and $32 \%$ at 24 months. The rates of complete remission without steroids were very low at $6,12,18$ and 24 months (between $0 \%-6 \%$ ) but our patients were not asked to follow a glucocorticoid tapering scheduled for complete withdrawal of prednisone after 6 months and were usually maintained under lowdose prednisone. Relapse rates were high between 18 and 24 months both in the total group and in the severe disease subgroup (due to the fact that rituximab is not reimbursed for maintenance treatment in Belgium). The subtype of ANCA was not predictive of the risk of relapse.

Conclusions: Our results confirm - in a "real-life" cohort of patients selected according data of RAVE trial - those of RAVE regarding complete remission rates at 6 months with prednisone $10 \mathrm{mg} / \mathrm{j}$. The high prevalence of relapses - in particular after 18 months - underlines the need to optimise maintenance treatment after an induction treatment with rituximab.

\section{REFERENCE:}

[1] Specks U, Merkel PA, Seo P, et al. Efficacy of remission-induction regimens for ANCA-associated vasculitis. N Engl J Med 2013:369(5):417-27.

Disclosure of Interest: None declared DOI: 10.1136/annrheumdis-2018-eular.1881

\section{SAT0528 \\ EFFECTIVENESS OF REMISSION-INDUCTION THERAPY WITH CONCOMITANT CYCLOPHOSPHAMIDE AND GLUCOCORTICOID FOR MICROSCOPIC POLYANGIITIS AND GRANULOMATOSIS WITH POLYANGIITIS IN JAPAN: A PROPENSITY SCORE MATCHED ANALYSIS OF TWO NATIONWIDE PROSPECTIVE COHORT STUDIES}

H. Watanabe ${ }^{1}$, K.-E. Sada ${ }^{1}$, Y. Matsumoto ${ }^{1}$, M. Harigai ${ }^{2,3}$, H. Makino ${ }^{4}$ on behalf of Japan Research Committee of the Ministry of Health, Labour, and Welfare for Intractable Vasculitis (JPVAS). ${ }^{1}$ Department of Nephrology, Rheumatology,

Endocrinology and Metabolism, Okayama University Graduate School of Medicine, Dentistry and Pharmaceutical Sciences, Okayama; ${ }^{2}$ Department of Pharmacovigilance, Graduate School of Medical and Dental Sciences, Tokyo Medical and Dental University; ${ }^{3}$ Division of Epidemiology and Pharmacoepidemiology of Rheumatic Diseases, Institute of Rheumatology, Tokyo Women's Medical University, Tokyo; ${ }^{4}$ Okayama university, Okayama, Japan

Background: Although concomitant use of cyclophosphamide (CYC) with glucocorticoids (GC) is considered to be one of the standard remission-induction therapies for antineutrophil cytoplasmic antibody (ANCA) associated vasculitis over 30 years, there are few reports about clinical efficacy or effectiveness of CYC.

Objectives: To evaluate effectiveness and safety of concomitant CYC as remis sion induction therapy in Japanese patients with microscopic polyangiitis (MPA) and granulomatosis with polyangiitis (GPA) using data sets from two nationwide prospective cohort studies.

Methods: Newly diagnosed MPA and GPA patients treated with GC with or without CYC for remission-induction therapy were enrolled. The patients treated with other immunosuppressants or plasma exchange were excluded. A propensity score for the use of CYC was estimated using age, types of AAV, serum creatinine level, Birmingham Vasculitis Activity Score (BVAS), and initial GC dosage at baseline. After propensity score matching at 1:1, remission, overall survival, and end-stage renal disease (ESRD)-free survival rates, Vasculitis Damage Index (VDI), and incidence of serious infection within 6 months were compared between patients treated with and without concomitant CYC.

Results: Of enrolled 327 patients, concomitant CYC was used in 119 (36\%) patients during the initial 3 weeks of treatment. After propensity score matching 95 patients with concomitant CYC (CYC group) and 95 controls (non-CYC group) were selected. Demographics, baseline characteristics and treatments were balanced between the two groups except for myeloperoxidase ANCA positivity (Table). The remission within 6 months was achieved in $85 \%$ in both groups. The survival and ESRD-free survival rates were also similar between the two groups (log-rank test; $p=0.77$ and 1.0, respectively). Median VDI at the time of last observation did not differ between the two groups (CYC, 3 [interquartile $\{\mathrm{IQR}\}: 2-4$ ] non-CYC, 2 [IQR:1-3], $p=0.26$ ). The accumulated $G C$ dosage of the CYC-group from 3 to 24 months was lower than the non-CYC group, the GC-related damage did not differ (CYC, 1 [IQR: 0-2]; non-CYC, 0 [IQR:0-2], p=0.69).

Table. Comparison of patients treated with concomitant cyclophosphamide and with glucocorticoid alone

\begin{tabular}{lccc}
\hline Variables at baseline and treatments & $\begin{array}{c}\text { Cyclophosphamide users } \\
(\mathrm{n}=95)\end{array}$ & $\begin{array}{c}\text { Non-users } \\
(\mathrm{n}=95)\end{array}$ & $p$-value \\
\hline Male/female, $\mathrm{n}$ & $51 / 44(46 \%)$ & $60 / 35$ & 0.24 \\
Age, years & $70(65-78)$ & $71(62-75)$ & 0.92 \\
GPA/MPA & $26 / 69$ & $27 / 68$ & 1.0 \\
Myeloperoxidase ANCA, $\mathrm{n}(\%)$ & $78(82)$ & $89(94)$ & $0.02^{*}$ \\
Proteinase-3 ANCA, $\mathrm{n}(\%)$ & $17(18)$ & $8(8)$ & 0.15 \\
Serum creatinine, mg/dL & $1.2(0.8-3.2)$ & $1.1(0.7-2.5)$ & 0.39 \\
C-reactive protein, mg/dL & $7.5(2.3-12.6)$ & $7.2(2.1-11.7)$ & 0.35 \\
BVAS & $15(12-20)$ & $16(12-21)$ & 0.99 \\
Interstitial lung disease, $\mathrm{n}(\%)$ & $38(40)$ & $37(49)$ & 0.55 \\
Glucocorticoid (mg/kg/day) ${ }^{\mathrm{d}}$ & $0.83(0.72-0.97)$ & $0.83(0.67-0.99)$ & 0.89
\end{tabular}

Values expressed as a number of patients (\%) or median (interquartile). ${ }^{*} \mathrm{p}<0.05$.

Conclusions: In Japanese patients with MPA and GPA, concomitant CYC could not show any benefits on clinical outcomes within 24 months. Dosage and treatment duration of CYC, as well as tapering methods of GC, could be confounding factors. Longer observation may be necessary to confirm the effectiveness of CYC as GC sparing agent.

Disclosure of Interest: None declared

DOI: 10.1136/annrheumdis-2018-eular.1689 